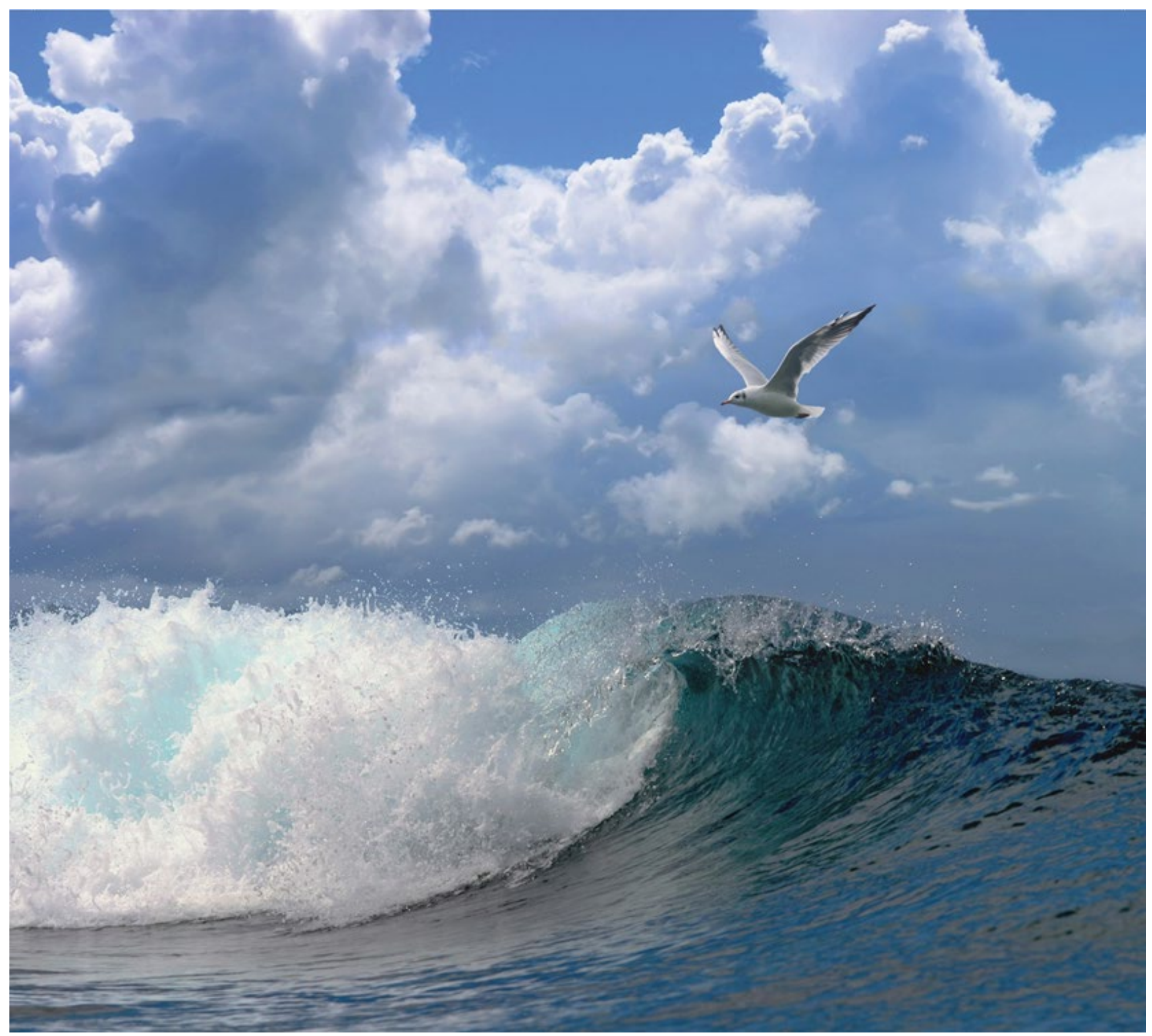

\title{
Comparison of length measurements of the blue whiting samples
}




\section{Comparison of length measurements of the blue whiting samples}

Author(s): Sakinan, S.

Wageningen Marine Research 
Keywords: blue whiting, length distribution, commercial catch.

Client: $\quad$ Pelagic Freezer-trawler Association (PFA)

Attn.: Martin Pastoors

Louis Braillelaan 80

2719 EK Zoetermeer

This report can be downloaded for free from https: https://doi.org/10.18174/555053

Wageningen Marine Research provides no printed copies of reports

Wageningen Marine Research is ISO 9001:2015 certified.

\section{(C) Wageningen Marine Research}

Wageningen Marine Research, an institute within the legal entity Stichting Wageningen Research (a foundation under Dutch private law) represented by Dr.ir. J.T. Dijkman, Managing director

KvK nr. 09098104, WMR BTW nr. NL 8113.83.696.B16.

Code BIC/SWIFT address: RABONL2U IBAN code: NL 73 RABO 0373599285
Wageningen Marine Research accepts no liability for consequential damage, nor for damage resulting from applications of the results of work or other data obtained from Wageningen Marine Research. Client indemnifies Wageningen Marine Research from claims of third parties in connection with this application.

All rights reserved. No part of this publication may be reproduced and / or published, photocopied or used in any other way without the written permission of the publisher or author. 


\section{Contents}

Comparison of length measurements of the blue whiting samples

Summary

$1 \quad$ Introduction

$2 \quad$ Materials and Methods $\quad 6$

$3 \quad$ Results $r 10$

$\begin{array}{lll}3.1 & \text { Vessel by vessel comparison } & 10\end{array}$

$\begin{array}{lll}3.1 .1 & \text { Year } 2017 & 10\end{array}$

3.1.2 Year $2018 \quad 11$

$\begin{array}{lll}3.2 & \text { Exceptional cases } & 14\end{array}$

$\begin{array}{ll}3.3 & \text { Local variability - the replicates } \\ \end{array}$

$4 \quad$ Conclusions and recommendations $\quad 17$

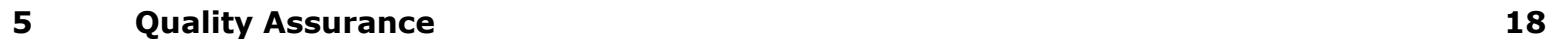

$\begin{array}{lr}\text { References } & 19\end{array}$

$\begin{array}{lr}\text { Justification } & 20\end{array}$ 


\section{Summary}

Blue whiting (Micromesistius poutussou) form dense spawning aggregations along the Hebridean Shelf and Porcupine Bank, west of Scotland and Ireland, starting early spring until May. The International Council for the Exploration of the Seas (ICES) coordinated the international scientific acoustic survey targeting this spawning aggregation of the blue whiting which provide indices of abundance per ageclass, which are an essential input data source for the assessment of this stock. The commercial fishing effort overlap with the survey in area and time. A first step towards the use of commercial length frequency data for survey index calculation is to investigate if there is any difference between survey and commercial length frequency data, and understand the origin of potential differences. In this study, the length frequency data collected by the self-sampling program on PFA vessels during the blue whiting fishing trips was compared with the survey measurements with a main focus on the 2017 and 2018 data. From different vessels contributing to the data set, only 4 vessels had adequate overlap in space and time in 2018, and 2 vessels in 2017. The results indicated that the mean length and the distributions are promisingly similar from two of the vessels contributing to this dataset in 2018. In addition, the third vessel showed very high similarity when the sampling dates are very close to the survey station while geographical distance is below 20 nautical miles. In 2017, the measurements from the two vessels had very close similarity to the survey measurements. As further supporting these close similarities, the mean length from a single survey samples (that were focus of the comparisons) remained within the $95 \%$ confidence interval of the measurements from the repeated hauls of PFA vessels in relatively close location. In 2018, one of the vessels contributing to the data did not have adequate similarity based on the statistical comparisons, however its samples also did not have very close overlap with survey samples in space and time compared to the other vessels. 


\section{Introduction}

Blue whiting (Micromesistius poutussou) aggregates in one particular region around west of Ireland for spawning during the early spring (Payne et. al, 2012). The International Council for the Exploration of the Seas (ICES) coordinated the international scientific acoustic survey targeting this spawning aggregation of the blue whiting which provides indices of abundance per age-class, which are an essential input data source for the assessment of this stock (ICES 2019). These survey indices are derived from acoustic data collected by echo-sounders (informing on the overall biomass), and catches providing information on the length composition of the biomass detected (later transformed into agecomposition). For operational reasons, the number of trawl operations is necessarily limited, and the length frequency data used to derive age-disaggregated indices are uncertain. Data collected from fishing vessels can be an alternative source to overcome spatial and temporal gaps in survey samples. Catch data including species composition and length distribution are recorded routinely during each fishing trip using systematic and standardized sampling protocols within a data collection program (selfsampling) implemented by the Pelagic Freezer-trawler Association (PFA).

The commercial fishing effort overlap with the survey in area and time. The scientific survey protocol requires representative fish samples collected throughout the survey area with pelagic trawl nets. In addition to the verification of the species composition, the samples are necessary also for obtaining length composition as well as other biological data such as age, sex and maturity stage. Furthermore, the acoustic backscatter is converted to abundance by using length dependent target strength, where the input for length distribution comes from representative trawl hauls ( Pedersen et al, 2011). Because of the spatio-temporal overlap between the survey and fishing effort, the commercial vessels may have hauls in the vicinity of the survey transects which can provide samples to be used for scientific purpose. For instance, the data coming from self-sampling database may be directly usable for this purpose (Pastoors et al, 2019). A first step towards the use of commercial length frequency data for survey index calculation consists of investigating the potential difference between survey and commercial length frequency data, and understand the origin of such differences.

However, the gears and fishing strategies are different between fishing vessels and research vessels, which potentially results in differences in catchability and selectivity, as well as differences in sampling errors resulting from the randomisation method. In order to address these questions, the fishery and research carried out on the blue whiting stock in the North-East Atlantic can be one potential case study. This study aims to compare and assess the congruence in length measurements between the scientific survey and commercial length frequency data. 


\section{Materials and Methods}

A statistical comparison has been performed between blue whiting length measurements during the International Blue Whiting Spawning Stock Survey (IBWSS) from the FRV/Tridens and self-samples from the PFA vessels overlaps with that period. In the PFA data set, length measurements from 8 different vessels in 4 different years (2015-2018) were available. In this report, these vessels have been referred to by pseudonyms from FV1 to FV8. The highest number of different ships and the widest geographical coverage belonged to 2018 and, for this reason, is the focus of this study. At this year the dataset consisted of 6 different vessels and 878 separate hauls (Table 1 ).

Table 1 Total number of self-sampled hauls per year and vessel during the blue whiting fishery

\begin{tabular}{c|llllllll} 
Year & FV1 & FV2 & FV3 & FV4 & FV5 & FV6 & FV7 & FV8 \\
\hline 2015 & 73 & 0 & 0 & 0 & 0 & 22 & 0 & 0 \\
2016 & 150 & 0 & 47 & 0 & 0 & 0 & 0 & 0 \\
2017 & 89 & 0 & 34 & 30 & 115 & 0 & 5 & 0 \\
2018 & 99 & 89 & 238 & 214 & 0 & 0 & 21 & 217
\end{tabular}

In 2018, the effective blue-whiting survey period for Tridens was between 20/3/2018 and 4/4/2018, where samples from 13 different stations were collected. In 2017 , the survey was between 16/3/2017 and $2 / 4 / 2017$, and similarly 13 different stations were sampled.

From each of the 6 self-sampling vessels that contributed to the dataset in 2017 and 2018, the closest haul to each of the survey haul was selected, where 273 pairs were available for 2017 and 878 pairs were available for 2018. Based on geographical distance and differences in date between the selfsampling and survey hauls, a proximity index was calculated. A scoring from 1 to 5 was rendered based on following intervals for both geographical distances and time differences;

\begin{tabular}{l|lllll} 
Scores & 1 & 2 & 3 & 4 & 5 \\
$\begin{array}{l}\text { Distances (nmi) } \\
\begin{array}{l}\text { Differences in dates } \\
\text { (days) }\end{array}\end{array}$ & $0-5$ & $5-10$ & $10-20$ & $20-50$ & $50-\max$ \\
& $0-7$ & $7-12$ & $12-15$ & $15-20$ & $20-\max$ \\
& & & & &
\end{tabular}

A lower score indicates the closest to the pairs. Figure 2.2 illustrates the proximities based on the closest samples from each self-sampling vessel against each survey haul. Despite the geographical overlap, not all the aforementioned hauls were coincided with the survey hauls in date. Only 189 samples, taken from 4 vessels overlapped with the time span from one week before the start of the survey to one week after the end of the survey in 2018 and 78 samples from the 2 vessels in 2017. Therefore comparisons were further narrowed down to these samples. Geographical positions of these overlapping hauls are shown in Figure 2.4 and Figure 2.3. Several of the stations sampled during the survey do not have selfsampling measurements in a nearby location for the survey period. The stations that can be considered within comparable distance/time and, therefore, acceptable for a comparison are shown on the maps in Figure 2.5 for the year 2017 and Figure 2.6 for the year 2018. 


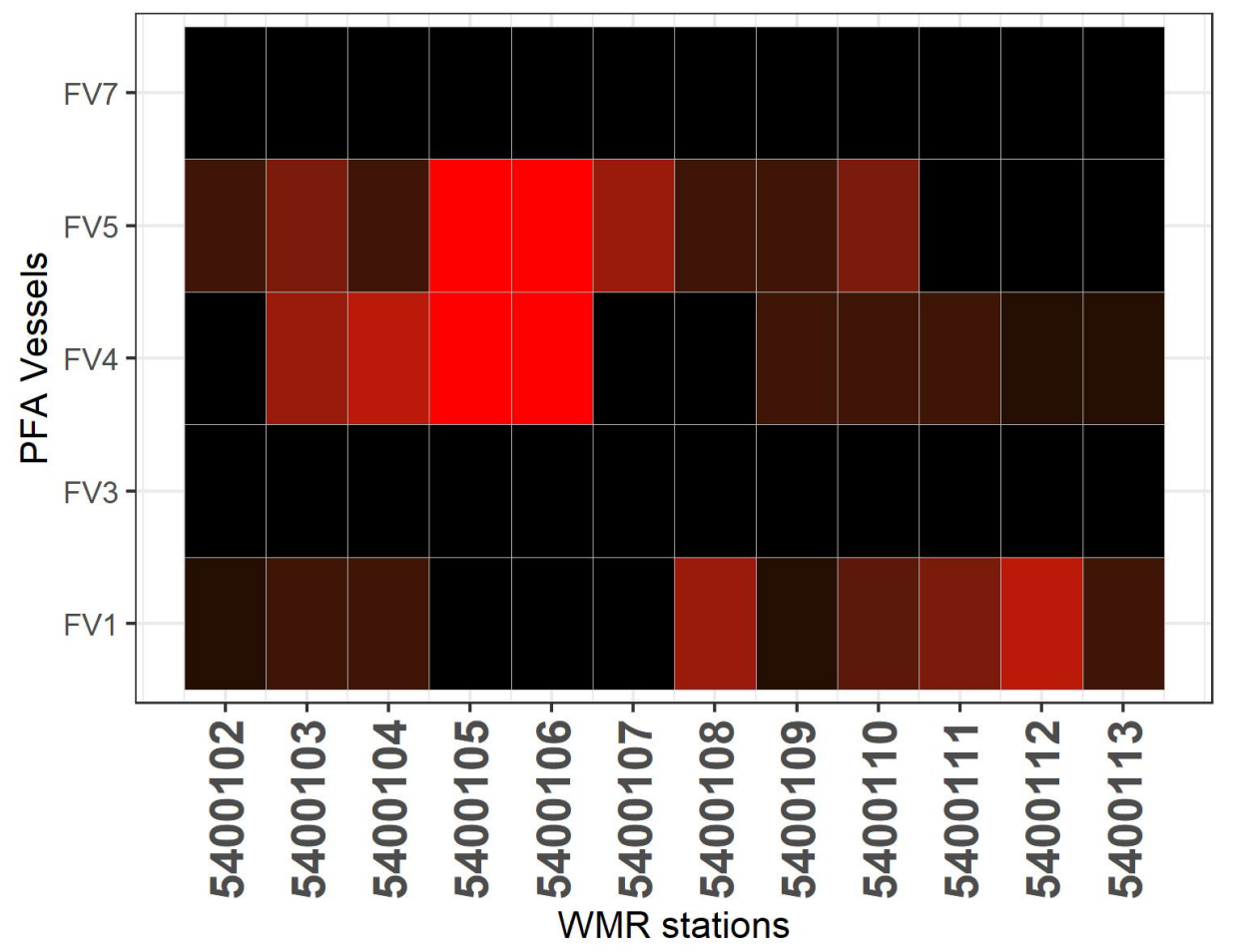

Figure 2.1 The proximity index matrix for the year 2017 showing distance between the survey stations and self-sampling. Colors indicate geographical distance and date differences between the survey hauls and the nearest self-sample hauls. Lower proximity scores correspond with closer samples.

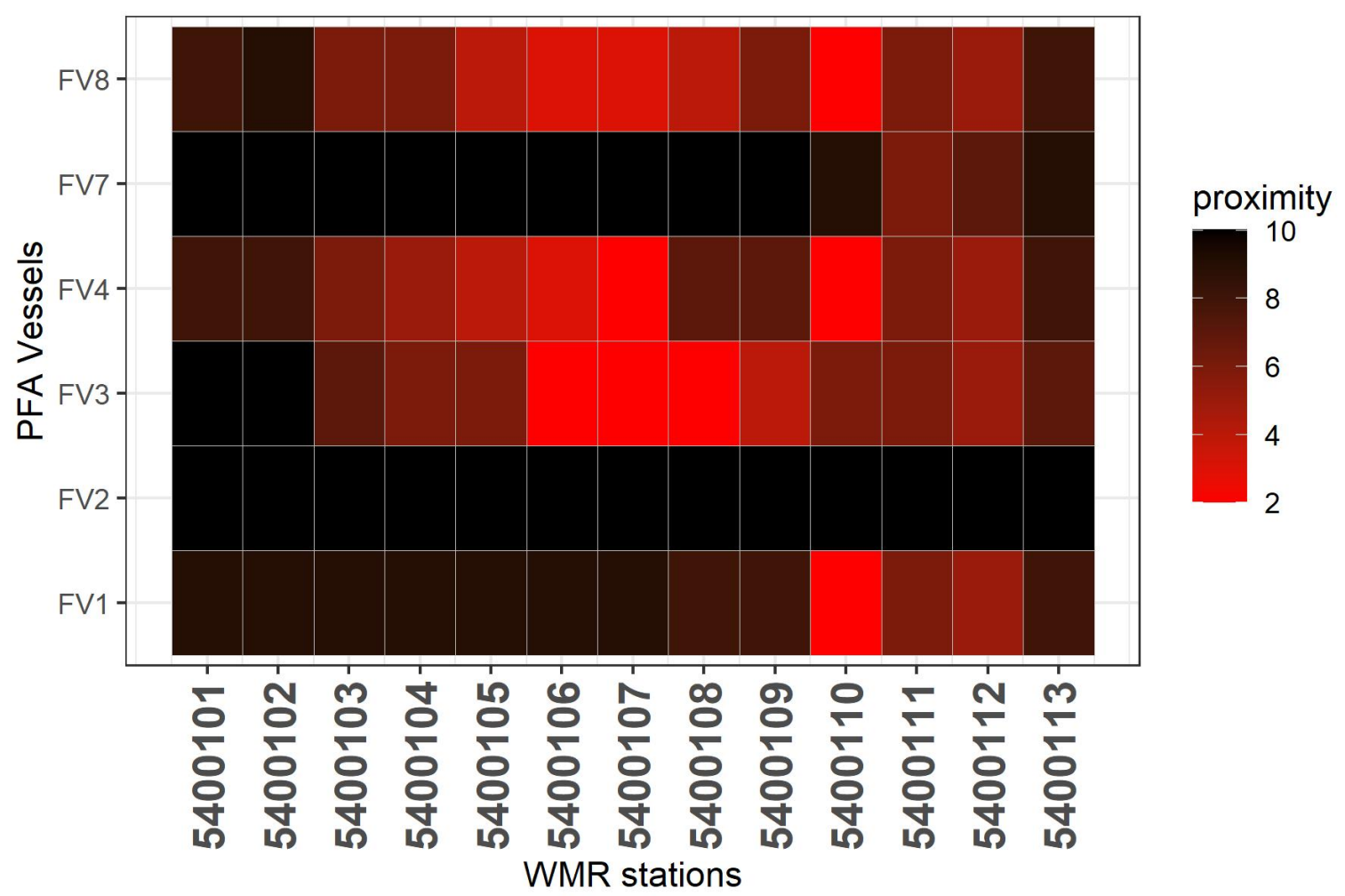

Figure 2.2 The proximity index matrix for the year 2018 showing distance between the survey stations and self-sampling. Colors indicate geographical distance and date differences between the survey hauls and the nearest self-sample hauls. Lower proximity scores correspond with closer samples. 
Self sampling hauls vs Tridens hauls within the survey period in 2017
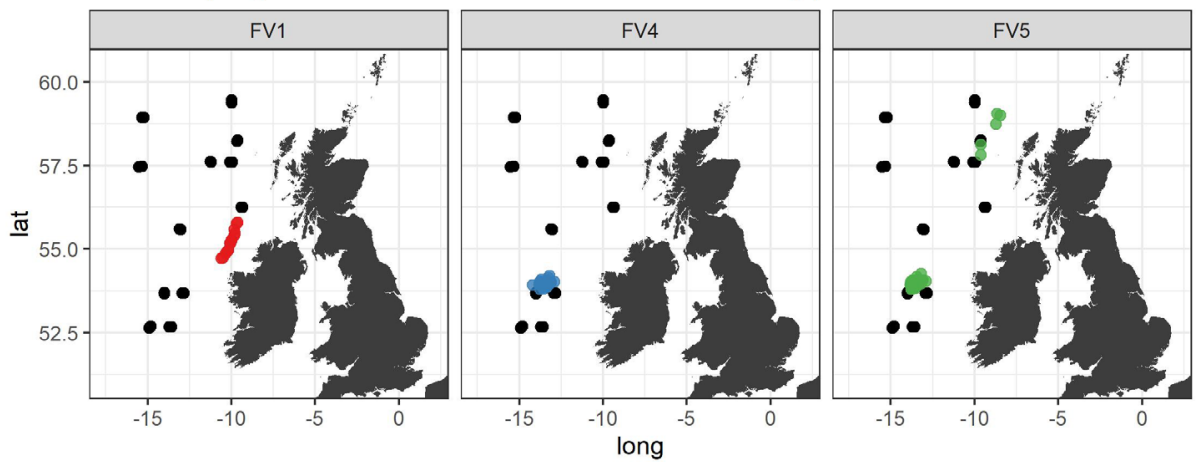

SelfSamplingVessel

- FV1

- FV4

- FV5

SurveyVessel

- Tridens

Figure 2.3 Maps showing the locations of self-sampling hauls relative to the survey hauls for the year 2017. Self-sampling locations corresponds to the period from one week before the start of the survey until one week after the end of the survey.

Table 2 Total number of hauls from 4 vessels that coincide with the survey period in 2018.

\begin{tabular}{c|cccc} 
Vessels & FV1 & FV3 & FV4 & FV8 \\
\hline $\begin{array}{c}\text { Proximity } \\
\text { Index }\end{array}$ & & & & \\
2 & 4 & - & 2 & 3 \\
3 & 4 & 2 & 5 & 21 \\
4 & 6 & 4 & 14 & 26 \\
5 & 4 & 26 & 16 & 16 \\
6 & 8 & 9 & 5 & 12 \\
7 & - & - & 2 & -
\end{tabular}

Self sampling hauls vs Tridens hauls within the survey period in 2018

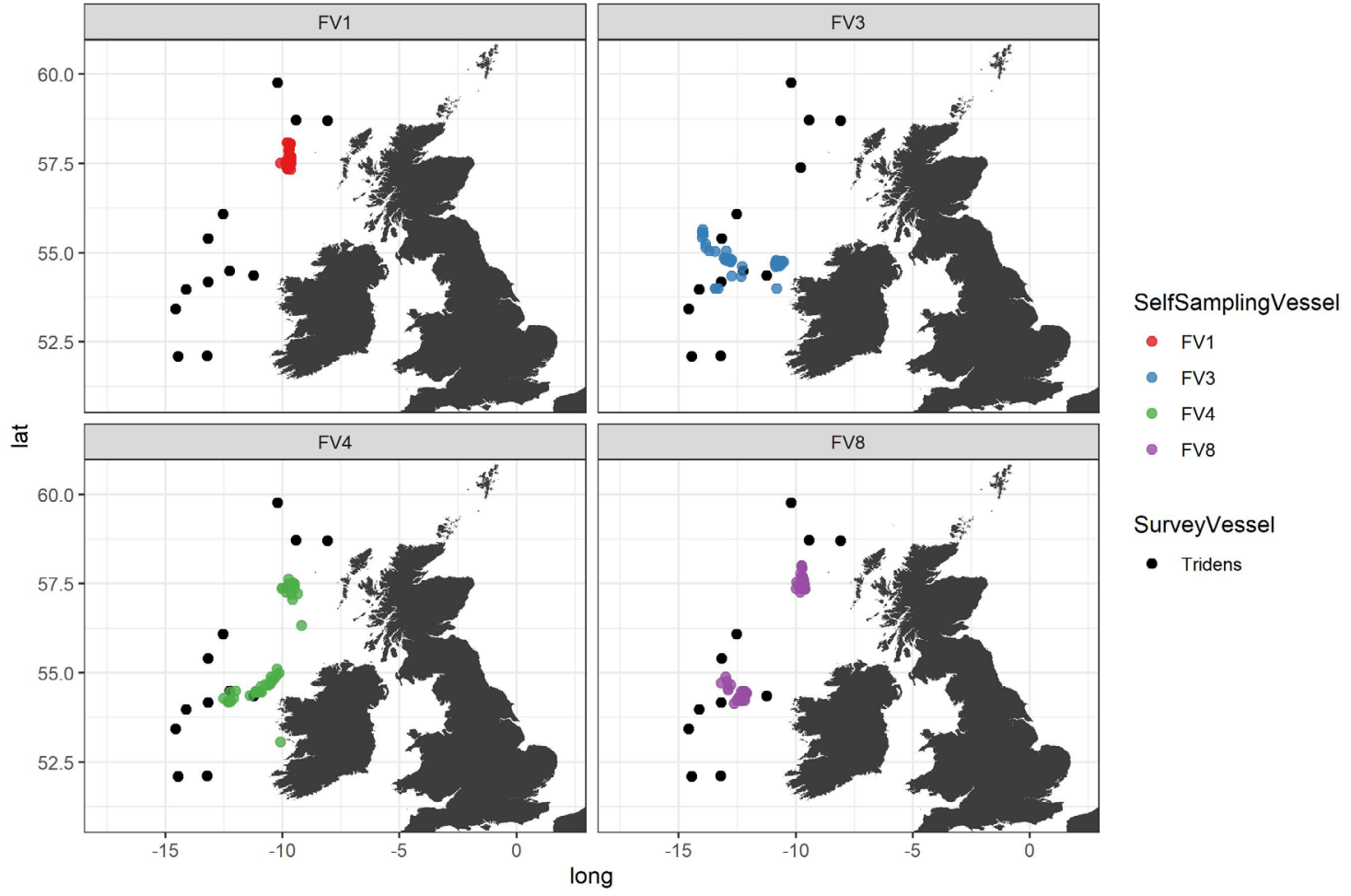

Figure 2.4 Maps showing the locations of self-sampling hauls relative to the survey hauls for the year 2018. Self-sampling locations corresponds to the period from one week before the start of the survey until one week after the end of the survey. 


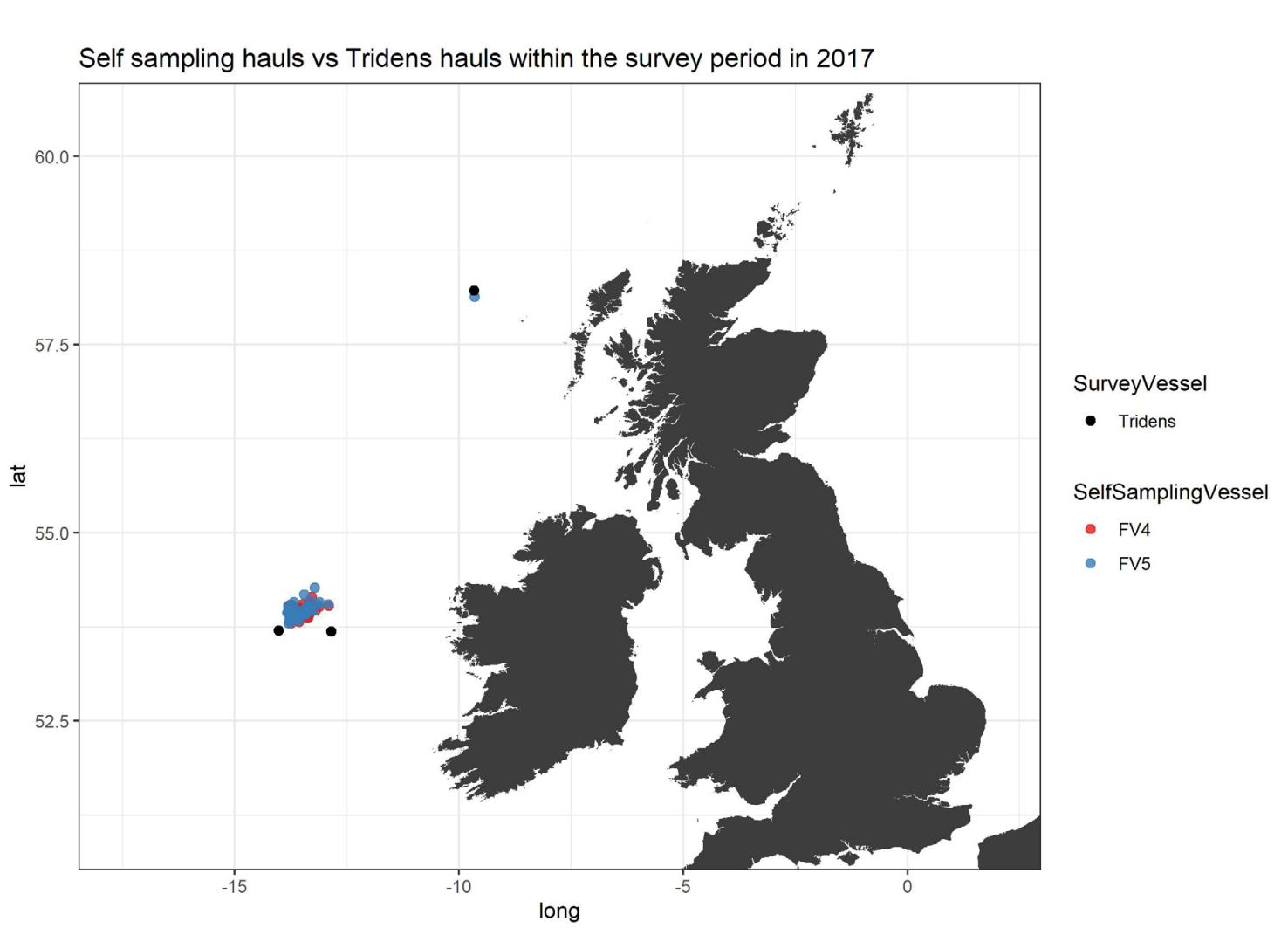

Figure 2.5 Locations of the closest samples that can be used in the comparisons for the year 2017.

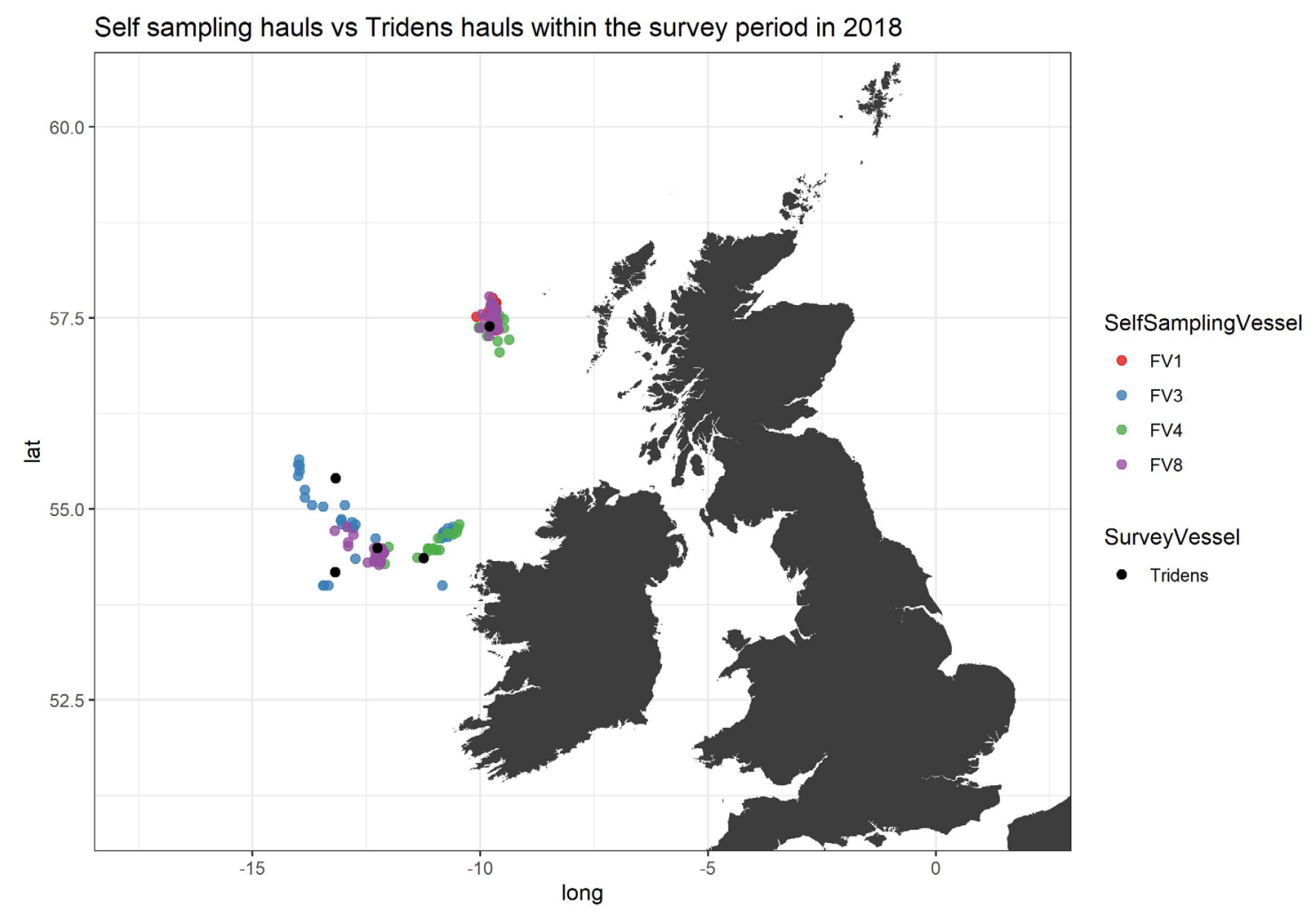

Figure 2.6 Locations of the closest samples that can be used in the comparison for the year 2018. 


\section{Results}

\subsection{Vessel by vessel comparison}

Comparisons were performed between the survey vessel samples, and samples from the self-sampling dataset by separately focussing on each vessel for year 2017 and 2018.

\subsubsection{Year 2017}

For the blue whiting fishery in 2017, data from five different vessels were available while only two of them had hauls in close proximity to the survey hauls. As in the case of 2018, the length frequency distributions were highly similar between the survey and self-sampling measurements illustrated on Figure 3.5 and Figure 3.6.
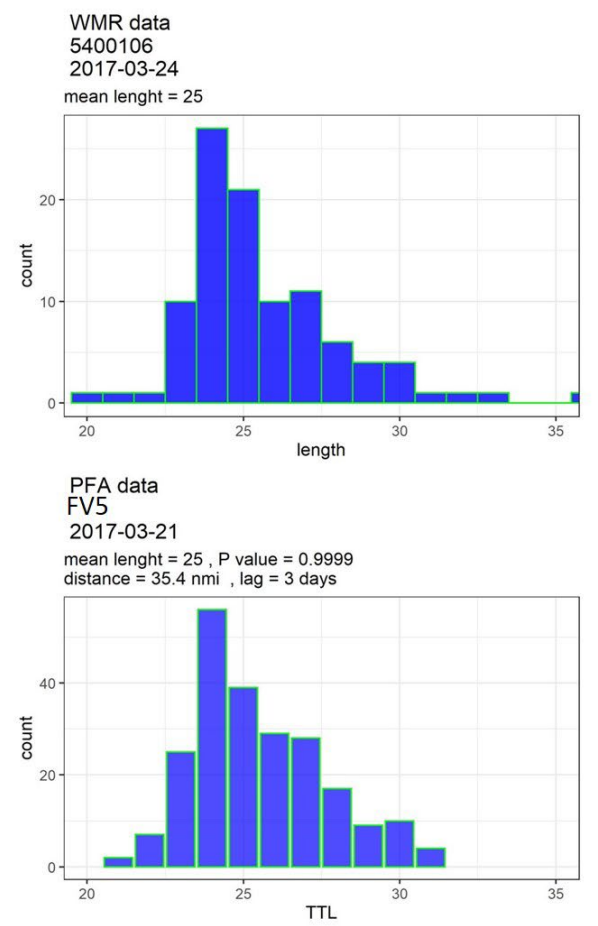
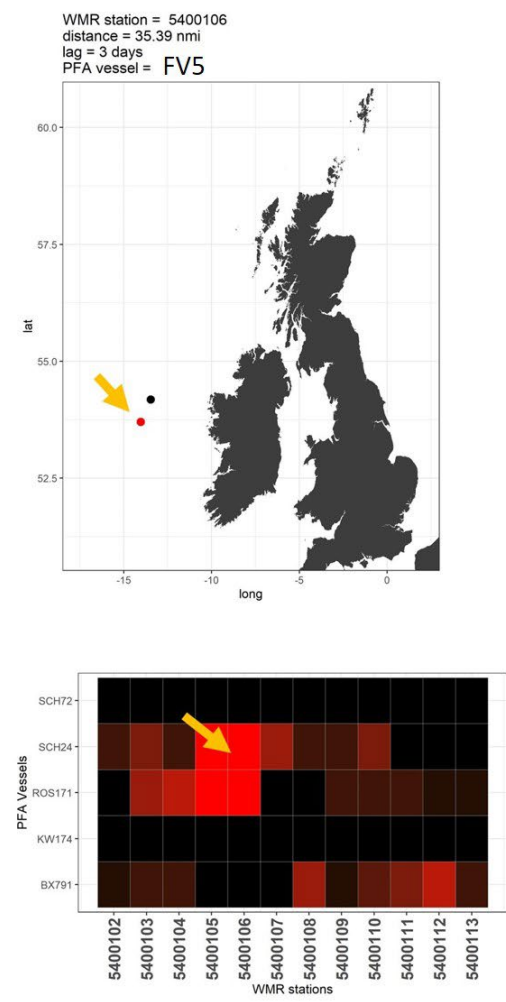

Two-sample KolmogorovSmirnov test p-value $=0.99$ No statistical difference between the length distributions $(P>0.05)$

Figure 3.1 An example of comparisons from the year 2017. Similar to earlier examples, the statistical distributions are highly similar with the same mean length of $25 \mathrm{~cm}$. 


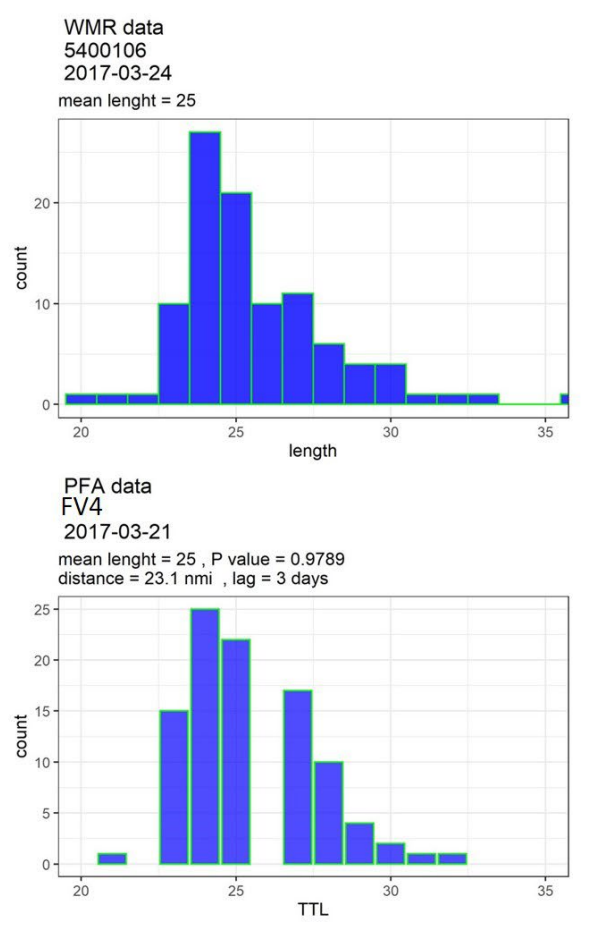

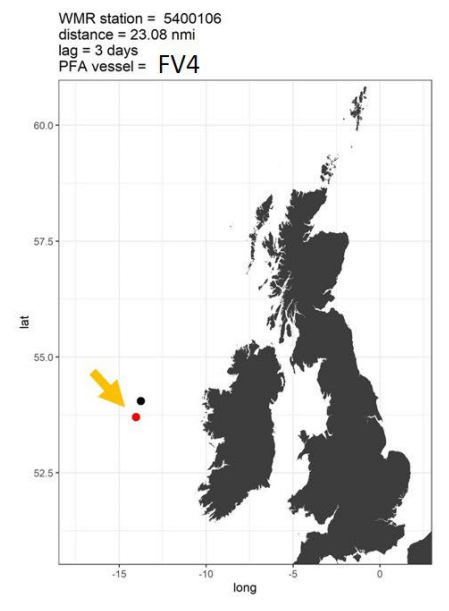

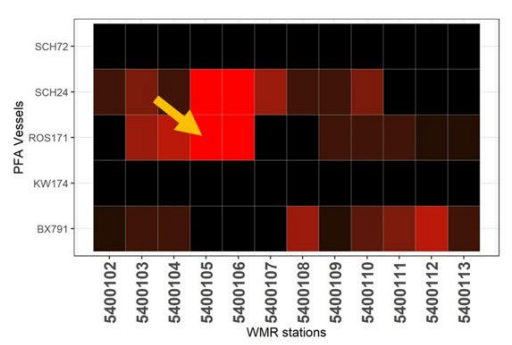

Two-sample KolmogorovSmirnov test $\mathrm{p}$-value $=0.98$ No statistical difference between the length distributions $(P>0.05)$

Figure 3.2 An example of comparisons from the year 2017. Similar to earlier examples, the statistical distributions are highly similar with the same mean length of $25 \mathrm{~cm}$.

\subsubsection{Year 2018}

For the year 2018, the first example shown in Figure 3.1 is one of the closest pairs in terms of date and location. The survey sample comes from station 5400107 and the self-sample data comes from vessel FV4. The lag time between these two samples were 4 days and the sampling locations were only 4.8 nautical miles apart. The statistical test ( Two-sample Kolmogorov-Smirnov test) resulted with a p-value $=0.23$ indicating that there is no statistically significant difference between the length measurements taken from these two different sets. Despite a slight difference $(0.5 \mathrm{~cm})$ in the mean, the results can be considered comparable. Similarly shown on Figure 3.2, another comparison based on another sample from the same vessel, show even higher similarity between the distributions (Two-sample KolmogorovSmirnov test, $\mathrm{p}$-value $=0.75)$ and the mean length of these samples are identical $(26 \mathrm{~cm})$. The lag time between these two samples, were 6 days and the sampling locations were only 3.9 nautical miles apart.

Figure 3.3 shows another example of the similarity between the survey and self-sampling measurements based on data from a different vessel (FV3). The distributions are almost identical with similarly right skewedness and same mean length $(27 \mathrm{~cm})$ despite the self-sampling data is relatively smaller in sub sample size. This is one of the closest pair between the survey station and self-sampling stations with only 2 days in between and 7.7 nautical miles between the starting points of the hauls.

Another example to the similarities comes from a haul from the vessel FV8 compared against the survey measurement at station 5400110 of Tridens. As shown in Figure 3.4. these stations were 17.4 nmi apart with 1 day differences between them, therefore can be assumed to be taking samples from the same aggregation. Although the distributions do not look as similar as the previous examples, the mean length $(26 \mathrm{~cm})$ are the same and Kolmogorov-Smirnov test indicated that the difference is not significant ( $P>0.05$ ). However, from the data it seems that the proportions of the most common length classes (26 and $27 \mathrm{~cm}$ ) in FV8 sample is substantially larger compared to the distribution from the Tridens sample. 


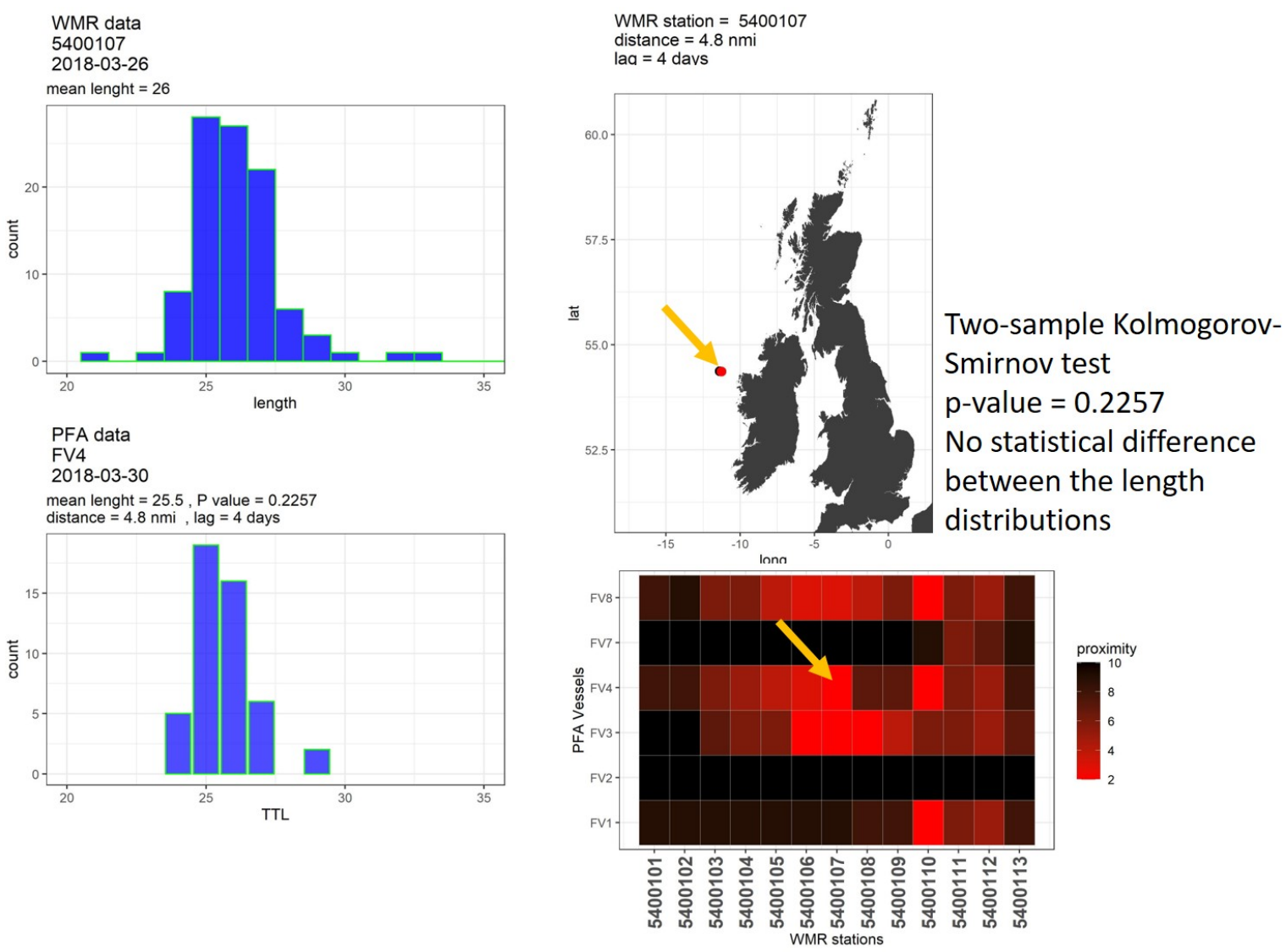

Figure 3.3 Results of comparison of one of the closest pairs. The histograms on the left panels shows the length distribution for the closest hauls, one is from the Tridens and the other is from FV4. The right panels show where these samples were located and their relative proximity within the dataset.
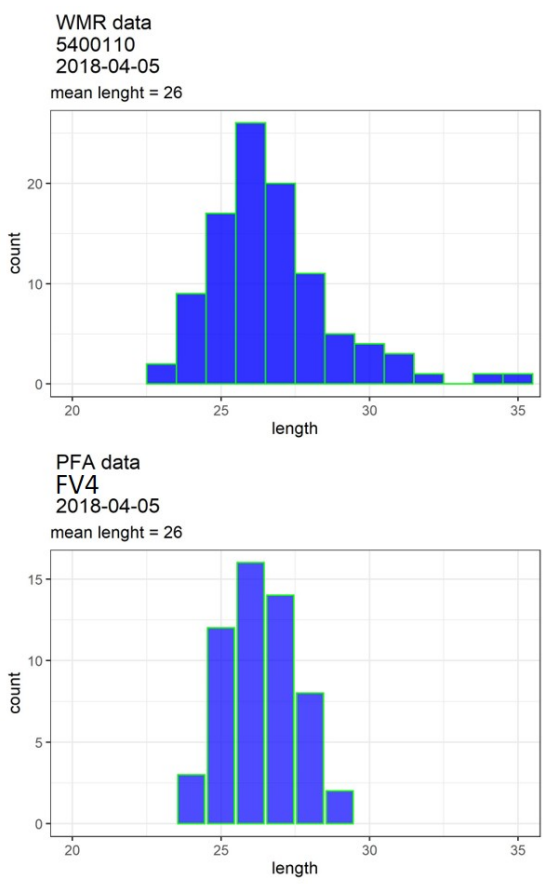

WMR station $=5400110$ distance $=3.9 \mathrm{~nm}$

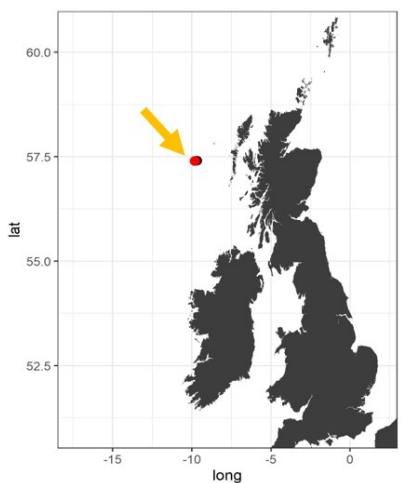

Two-sample Kolmogorov-

Smirnov test

$\mathrm{p}$-value $=0.7492$

No statistical difference

between the length

distributions

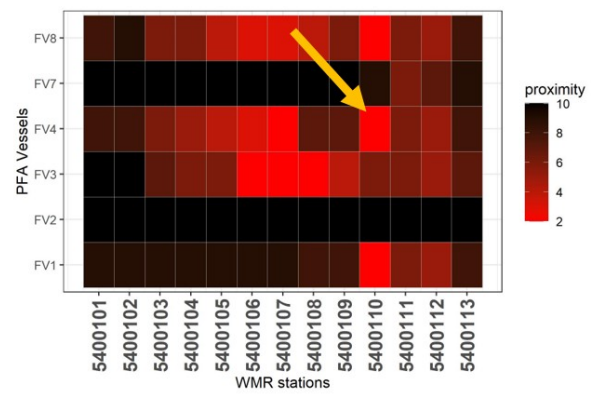

Figure 3.4 The figure shows another comparison between FV4 and Tridens. The right panels show where these samples were located and their relative proximity within the dataset. The mean length of these two samples are similar $(26 \mathrm{~cm})$ and there is no statistically significant difference between the distributions. 


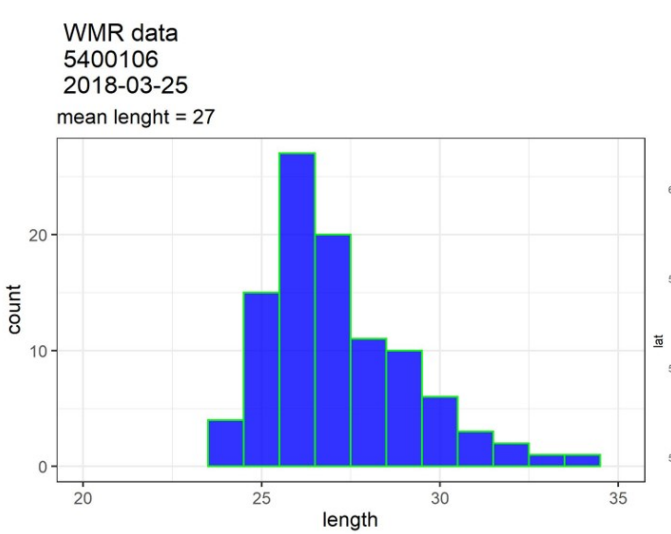

\section{PFA data}

FV3

2018-03-23

mean lenght $=27, \mathrm{P}$ value $=0.9007$

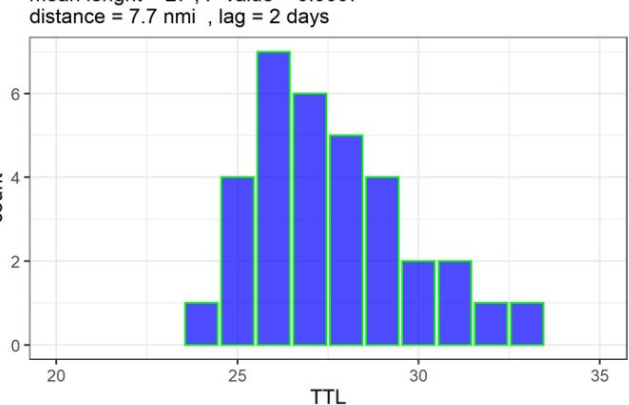

WMR station $=5400106$
distance $=7.7 \mathrm{nmi}$

distance $=7.7 \mathrm{nmi}$
lag $=2$ days

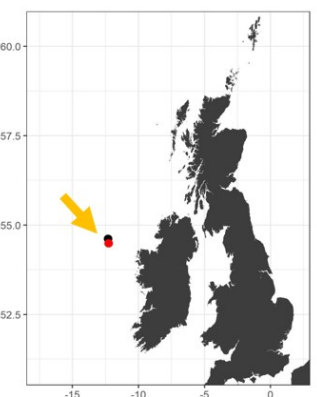

long

Two-sample Kolmogorov-

Smirnov test

p-value $=0.901$ No statistical

difference between the

length distributions

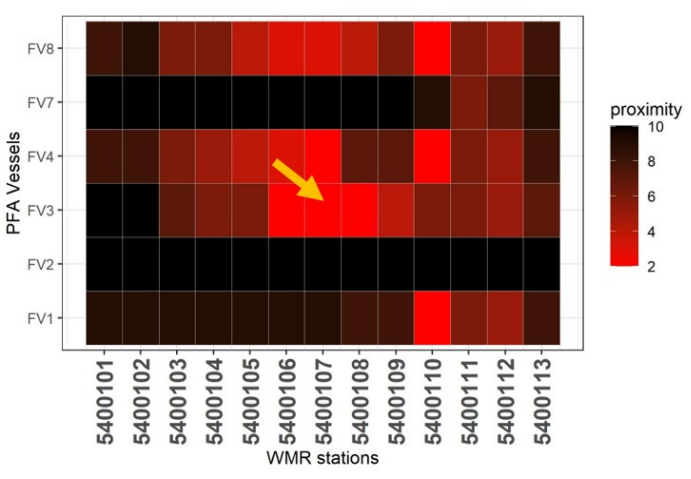

Figure 3.5 comparison between the survey station 5400106 of Tridens and the closest station from self-sampling platform FV3. The realization of hauls has 2 days in between and 7.7 nautical miles apart. The histograms shows almost identical distribution in length measurements where both station has the same mean length of $27 \mathrm{~cm}$.
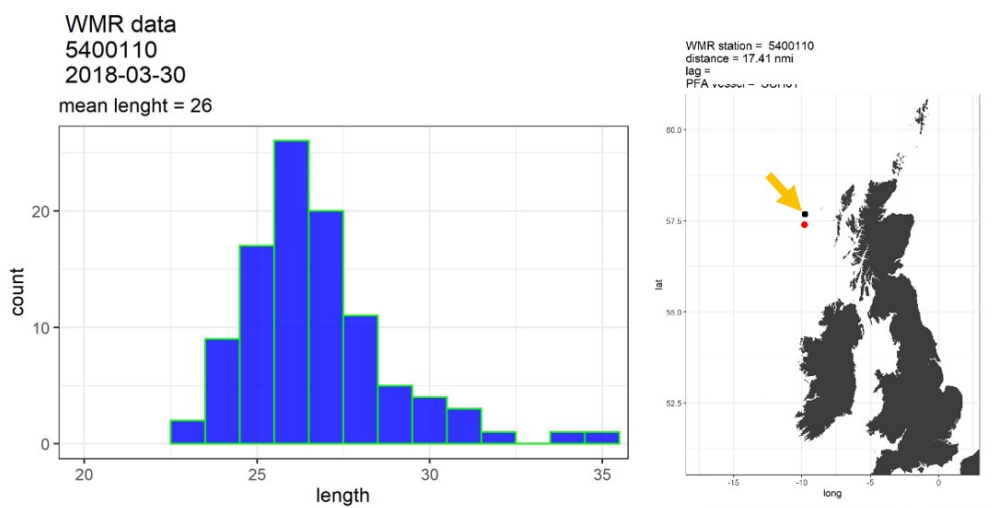

Two-sample KolmogorovSmirnov test p-value $=0.06$ No statistical difference between the length distributions $(P>0.05)$
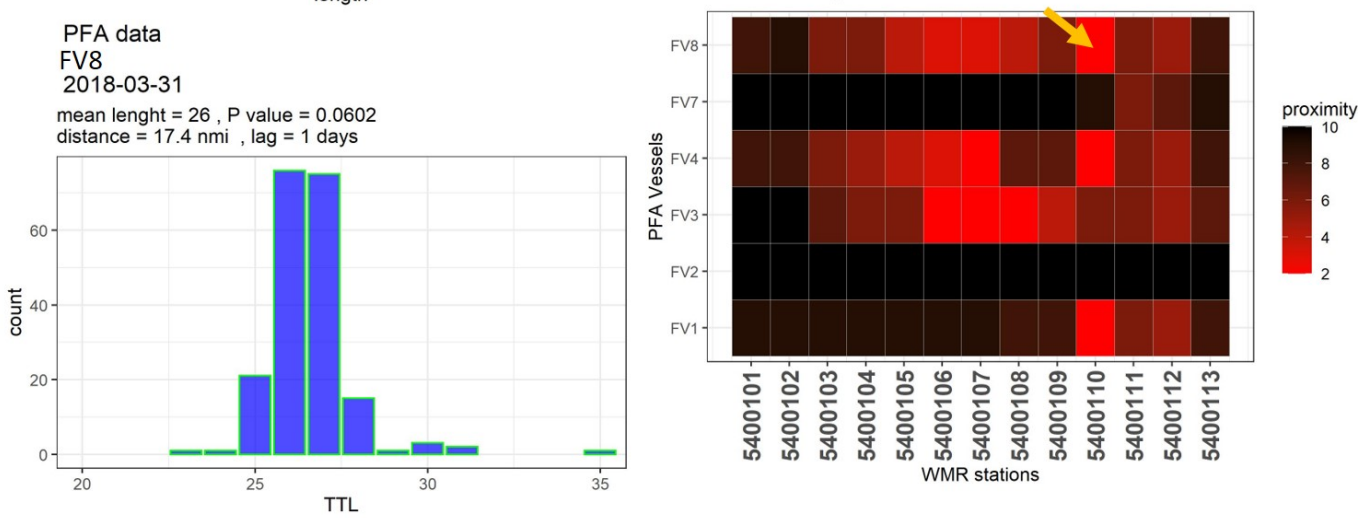

Figure 3.6 Another example of similarities between the survey length distribution and the selfsampling, comparison between the survey station 5400110 of Tridens and one of the closest station from self-sampling platform FV8. The realization of hauls has 1 days and 17.4 nautical miles in between. 


\subsection{Exceptional cases}

While the similarities between the length distributions of the samples from these two different ships and the survey measurement are promising, there are also some exceptions showing difference. For example the closest stations between the FV1 and Tridens showed differences in distributions and the mean lengths (Figure 3.7). Furthermore in FV8, despite the promising similarity in the previous example, there were few samples within the close vicinity with significant differences in the distributions (one of the cases shown in Figure 3.7).
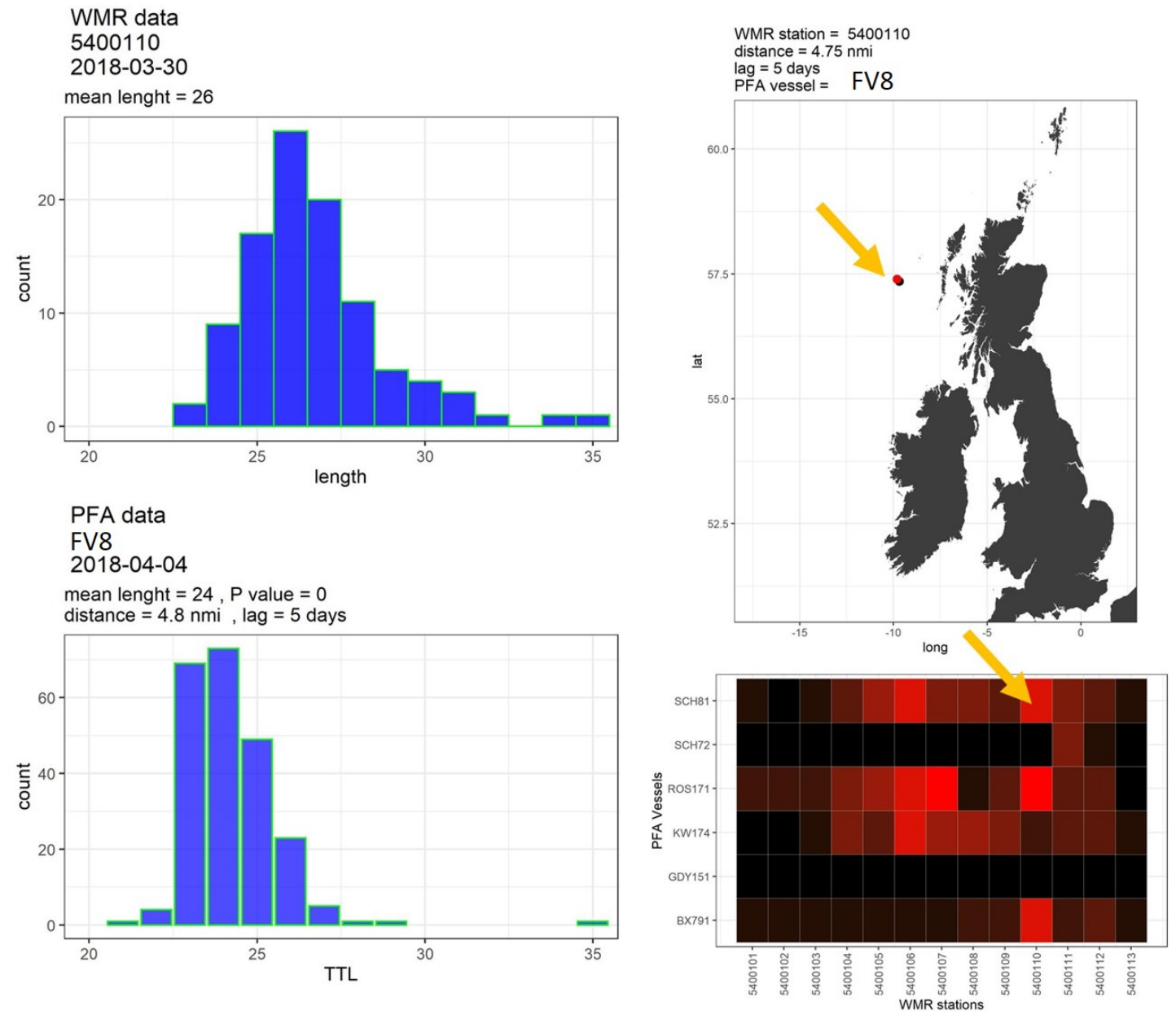

Figure 3.7 Comparison of the median length of the samples. The replicates are from the selfsampling dataset of FV4 from the locations surrounding the survey station 5400110 (Figure 5) in close proximity. The box plot on the right panel shows the distribution of the median lengths of the collocated hauls such that the center of the box is the overall median, size of the box are 25th and 75th quartiles, the lines show the minimum and maximum. The red dot show the median of the single survey station.

\subsection{Local variability - the replicates}

By design, the survey stations are sparsely distributed to cover a large area which does not allow for resolving the local sampling variability due to lack of replications in similar point in area and time. On the other hand, in self-sampling dataset, many repeated hauls with close proximity are available. Figure 3.8 shows the location of the self-sampling hauls surrounding the survey station within close location/date proximity. Samples from these collocated hauls can be considered as replicate samples. As can be seen on this plot, the centre of the replicated samples is very close to the single measurement from the survey station ( box plot on Figure 3.8). The median of the length distributions from measured from this vessel (FV4) is $26.45 \mathrm{~cm}$ while the median of the single survey station is $26.7 \mathrm{~cm}$ remaining within the confidence interval of this sample from the survey data $(26.17 \mathrm{~cm}-26.79 \mathrm{~cm})$. Similarly, this 
value remains within the confidence interval of the samples from the replicate stations of FV8 Figure 3.9.
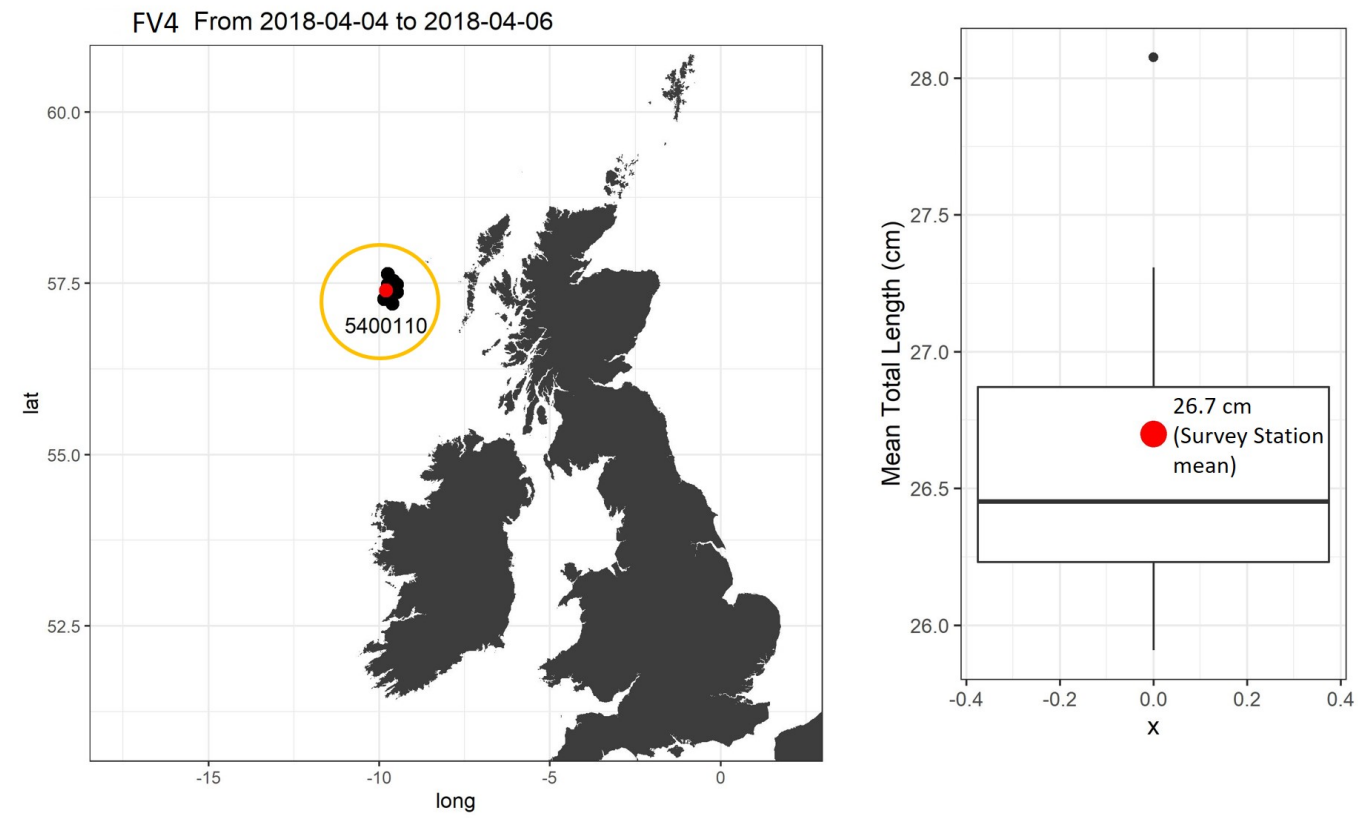

Figure 3.8 Comparison of the median length of the samples. The replicates are from the selfsampling dataset of FV4 from the locations surrounding the survey station 5400110 in 2018 . in close proximity. The box plot on the right panel shows the distribution of the median lengths of the collocated hauls such that the center of the box is the overall median, size of the box are $25^{\text {th }}$ and $75^{\text {th }}$ quartiles, the lines show the minimum and maximum. The red dot show the median of the single survey station.
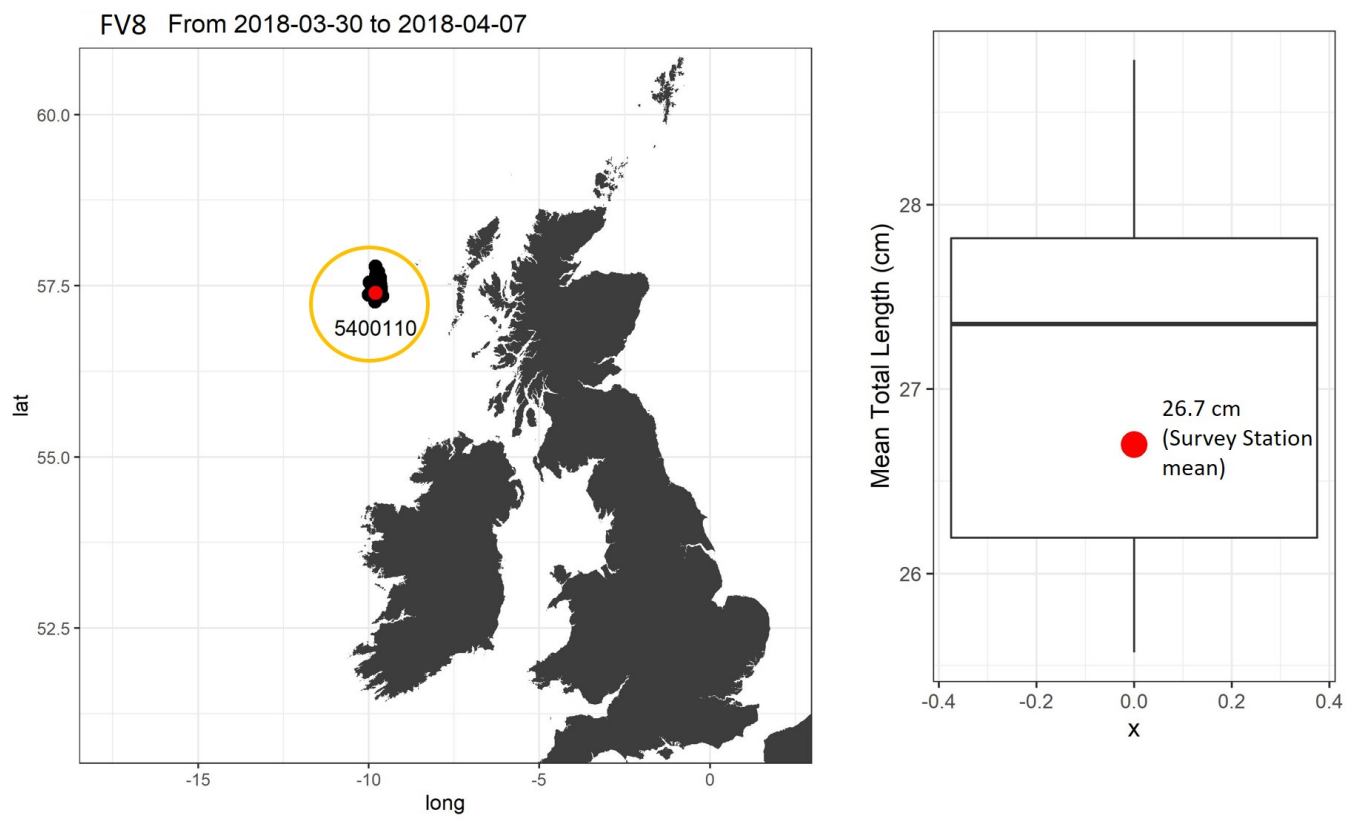

Figure 3.9 The replicates from the self-sampling dataset of FV8 from the locations surrounding the survey station 5400110 in 2018. Similar to previous figure, The box plot on the right panel shows the distribution of the median lengths of the collocated hauls such that the centre of the box is the overall median, size of the box are 25th and 75th quartiles, the lines show the minimum and maximum. The red dot show the median of the single survey station. 

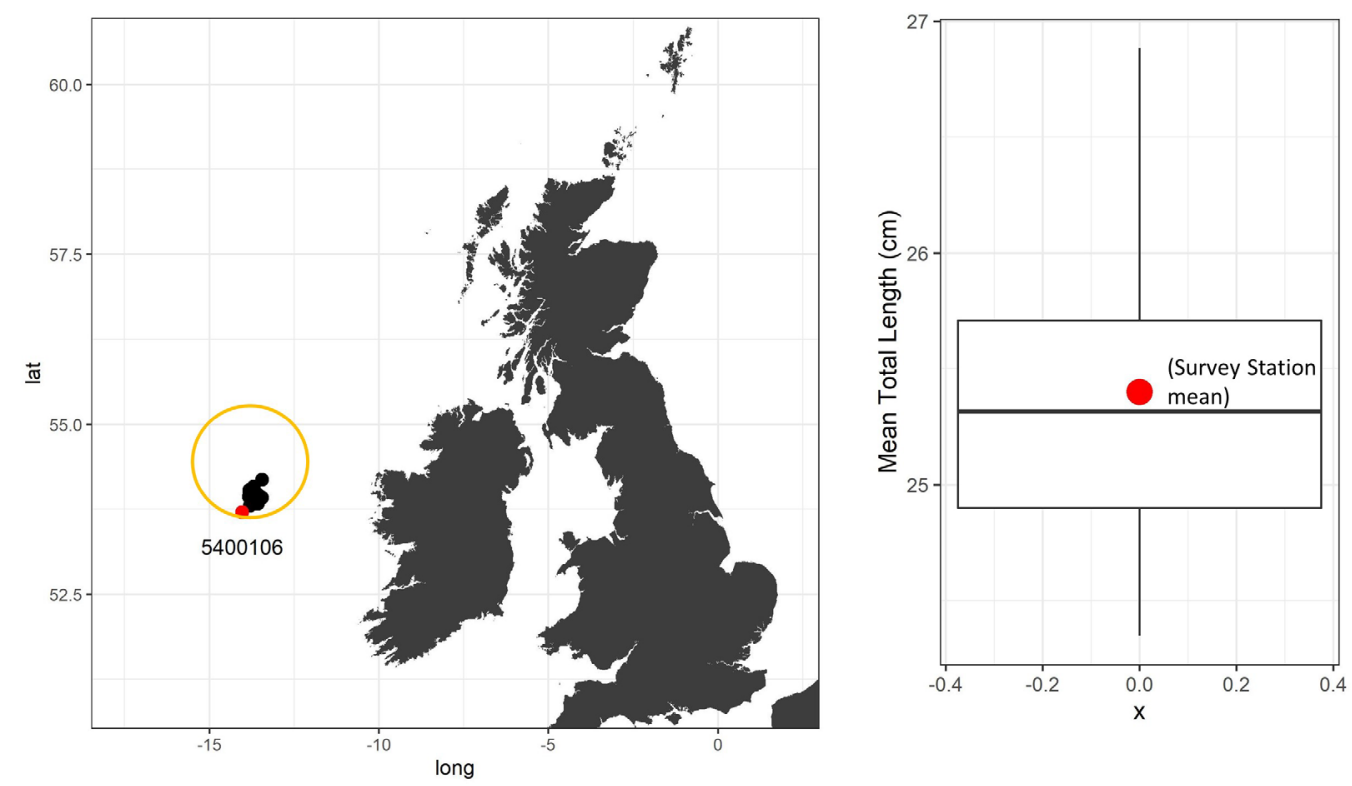

Figure 3.10 The replicates from the self-sampling dataset of FV5 from the locations surrounding the survey station 5400106 in 2017. The box plot on the right panel shows the distribution of the median lengths of the collocated hauls such that the center of the box is the overall median, size of the box are 25th and 75th quartiles, the lines show the minimum and maximum. The red dot show the median of the single survey station. 


\section{Conclusions and recommendations}

A detailed comparison has been carried out between the length frequency data sets between the PFAsampling measurements and the surveys measurements carried out on board of FRV/ Tridens during the blue whiting survey in 2017 and 2018. In 2018, from the 6 vessels contributed to this data set 4 vessel had samples in close proximity in location and time while in 2017 only 2 PFA vessels had samples from close proximity. The majority of these closely located samples had similarity in the length distribution and mean length without statistically significant differences between the compared pairs. Furthermore, the mean length from a single sample from the survey remained within the $95 \%$ confidence interval of the measurements from the repeated hauls of PFA vessels in relatively close location. These are promising results for the aim of incorporating this data into scientific stock assessment processes. However there are certain exceptions in the data set showing a significant difference in the mean length by $2-3 \mathrm{~cm}$, despite being similarly in close location. Such difference can be a result of either changed targeted depth in fishing or result of local overexploitation or an exceptional bias. It is known that some of the vessels perform measurements using different length units such as fork length rather than the total length. It is necessary to ensure that such factors are not impacting the data set and all the measurements in the data set have the same standards. Once such consistency in the quality is ensured, the results shows that the length measurements from the commercial vessels can be used to fill the data gaps for the scientific applications and they can also be safely incorporated into ecological studies or applications that assist the stock assessment. 


\section{Quality Assurance}

Wageningen Marine Research utilises an ISO 9001:2015 certified quality management system. This certificate is valid until 15 December 2021. The organisation has been certified since 27 February 2001. The certification was issued by DNV GL.

Furthermore, the chemical laboratory at IJmuiden has EN-ISO/IEC 17025:2017 accreditation for test laboratories with number L097. This accreditation is valid until $1^{\text {th }}$ of April 2021 and was first issued on 27 March 1997. Accreditation was granted by the Council for Accreditation. The chemical laboratory at IJmuiden has thus demonstrated its ability to provide valid results according a technically competent manner and to work according to the ISO 17025 standard. The scope (L097) of de accredited analytical methods can be found at the website of the Council for Accreditation (www.rva.nl).

On the basis of this accreditation, the quality characteristic $Q$ is awarded to the results of those components which are incorporated in the scope, provided they comply with all quality requirements. The quality characteristic $Q$ is stated in the tables with the results. If, the quality characteristic $Q$ is not mentioned, the reason why is explained.

The quality of the test methods is ensured in various ways. The accuracy of the analysis is regularly assessed by participation in inter-laboratory performance studies including those organized by QUASIMEME. If no inter-laboratory study is available, a second-level control is performed. In addition, a first-level control is performed for each series of measurements.

In addition to the line controls the following general quality controls are carried out:

- Blank research.

- Recovery.

- Internal standard

- Injection standard.

- Sensitivity.

The above controls are described in Wageningen Marine Research working instruction ISW 2.10.2.105. If desired, information regarding the performance characteristics of the analytical methods is available at the chemical laboratory at IJmuiden.

If the quality cannot be guaranteed, appropriate measures are taken. 


\section{References}

Høines, A., Couperus, B., Kvamme, C., O’Donnell, C., Mc Neill, G., Hátún, H., ... \& Auton, U. (2019). ICES Working Group of International Pelagic Surveys (WGIPS).

Pastoors, M. (2019). PFA self-sampling report 2015-2018.

Payne, M. R., Egan, A., Fässler, S. M., Hátún, H., Holst, J. C., Jacobsen, J. A., ... \& Loeng, H. (2012). The rise and fall of the NE Atlantic blue whiting (Micromesistius poutassou). Marine Biology Research, $8(5-6), 475-487$.

Pedersen, G., Godø, OR, Ona, E., \& Macaulay, GJ (2011). A revised target strength - length estimate for blue whiting (Micromesistius poutassou): implications for biomass estimates. ICES Journal of Marine Science , 68 (10), 2222-2228.

Pedersen, G., Godø, OR, Ona, E., \& Macaulay, GJ (2011). A revised target strength - length estimate for blue whiting (Micromesistius poutassou): implications for biomass estimates. ICES Journal of Marine Science , 68 (10), 2222-2228. 


\section{Justification}

Report C076/21

Project Number: 4316100171 (Calibr.of com.fishing vessels)

The scientific quality of this report has been peer reviewed by a colleague scientist and a member of the Management Team of Wageningen Marine Research

Approved: $\quad$ Katinka Bleeker

Researcher

Signature:

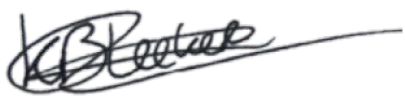

Date: $\quad 13^{\text {th }}$ of October 2021

Approved: $\quad$ Drs. Jakob Asjes

MT member Integration

Signature:

Date:

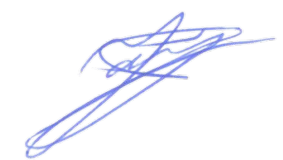

$13^{\text {th }}$ of October 2021 
Wageningen Marine Research

T +31(0)317480900

E: marine-research@wur.nl

www.wur.eu/marine-research

Visitors' address

- Ankerpark 271781 AG Den Helder

- Korringaweg 7, 4401 NT Yerseke

- Haringkade 1, 1976 CP IJmuiden
With knowledge, independent scientific research and advice, Wageningen Marine Research substantially contributes to more sustainable and more careful management, use and protection of natural riches in marine, coastal and freshwater areas.

Wageningen Marine Research is part of Wageningen University \& Research. Wageningen University \& Research is the collaboration between Wageningen University and the Wageningen Research Foundation and its mission is: 'To explore the potential for improving the quality of life' 